\title{
Neuropathology of cerebral arteriovenous malformations in children
}

\author{
S TAKASHIMA AND L E BECKER
}

From the Department of Pathology, The Hospital for Sick Children, Toronto, Ontario, Canada

SUMMARY Neuropathological findings in children who had died of cerebral arteriovenous malformation under 6 years of age were contrasted with those of children aged 6 to 15 years. In all subjects, the abnormalities were more marked in the shunting vessels and veins distal to the arteriovenous shunt than in the arteries. Fibrous thickening, calcification and adherent thrombus of vessel wall, and gliosis and haemosiderin in contiguous neural tissue were more common in the older than the younger children. Children less than 1 week old with vein of Galen malformations presented with congestive heart failure and "watershed" cerebral infarction; most of those over one week old had hydrocephalus and venous thrombosis with haemorrhagic infarction.

McCormick $^{1}$ suggested that congenital vascular malformations should include telangiectasia, varix, cavernous haemangioma, arteriovenous malformation (AVM) and venous malformation, but should exclude berry aneurysms. However, experience with vascular malformations in children is limited, because often these lesions do not present until after childhood.

In patients under 16 years old, the most common type is AVM, a tangled mass of tortuous and greatly dilated veins, supplied by an enlarged artery, with an interposed bed of dilated vessels in the position of the capillaries. The AVM increases greatly in size with age, but the mechanism of this increase is not clear. Aneurysms of the vein of Galen (AVG), one type of AVM, have an arteriovenous (AV) shunt and marked dilation of the vein of Galen and sinus system. We report on the neuropathology of AVM in children to clarify the relationship of their development to ageing.

\section{Methods}

We examined the clinical records, cerebral angiograms, and autopsy records of all children undergoing autopsy from January 1, 1958 to December 31, 1977 at The Hospital for Sick Children, Toronto, in whom AVM or AVG was

Address for reprint requests: Dr LE Becker, Department of Pathology, The Hospital for Sick Children, 555 University Avenue, Toronto, Ontario, Canada M5G 1 X8.

Accepted 10 December 1979 diagnosed. Samples of brain for histology had been taken and stained with haematoxylin and eosin (H\&E), luxol fast blue, cresyl violet, elastic van Gieson (EVG), and Azan-Mallory; the samples were from the frontal, motor, and visual cortices, hippocampus, basal ganglia, thalamus, midbrain, pons, medulla, cerebellum, spinal cord, and abnormal areas. Other organs had been examined routinely for vascular malformations.

\section{Results}

We found 28 cases of AVM, of which 16 were AVG.

1 Arteriovenous malformation (other than $A V G)$ All children with AVM had been over one year old at death: four were aged one to six years (group I) and eight aged seven to fifteen years (group II) (table 1). In subjects 2 , 3 , and 4 (in group I), onset of symptoms had been precipitous. No patient in group I had undergone angiography. At autopsy, subarachnoid, ventricular, or cerebral haemorrhage in the hemispheres (subjects nos 2 and 4), or pons (subject no 3) was found. Subject no 1 had an AVM with aneurysmal dilation and focal calcification in the frontal lobe, marked dilation of internal and external carotid arteries, and communicating hydrocephalus. The only other vascular malformation was a haemangioma of the psoas muscle in subject no 2 .

The AVMs were composed of dilated, thickwalled vessels of various sizes; it was difficult to determine which vessels were venous or arterial 
Table 1 Main features and test results in subjects with arteriovenous malformations

\begin{tabular}{|c|c|c|c|c|c|c|c|}
\hline Cases & Age at death & $\operatorname{Sex}$ & Signs and symptoms & Angiography & Operation & Location of $A V M$ & Neuropathology \\
\hline \multicolumn{8}{|c|}{ Group 1} \\
\hline 1 & $15 \mathrm{mth}$ & $\mathbf{M}$ & $\begin{array}{l}\text { Hydrocephalus } \\
\text { Seizures }\end{array}$ & No & Yes & $L$ frontal & $\begin{array}{l}\text { Hydrocephalus } \\
\text { Dilated carotid artery } \\
\text { SAH }\end{array}$ \\
\hline 2 & $19 \mathrm{mth}$ & $\mathbf{M}$ & $\begin{array}{l}\text { Vomiting } \\
\text { Coma }\end{array}$ & No & No & L temporoparietal & SAH, CH, thrombosis, neuronal oesinophilia \\
\hline 3 & $19 \mathrm{mth}$ & $\mathbf{F}$ & $\begin{array}{l}\text { Vomiting } \\
\text { Opisthotonus }\end{array}$ & No & No & Pons & SAH \\
\hline 4 & $2 \mathrm{yr}$ & $\mathbf{F}$ & $\begin{array}{l}\text { Headache } \\
\text { Stiff neck } \\
\text { Coma }\end{array}$ & No & No & L centrum semiovale & SAH, CH (old), VH, neuronal eosinophilia \\
\hline \multicolumn{8}{|c|}{ Group II } \\
\hline 5 & $8 \mathrm{yr}$ & $\mathbf{F}$ & R Hemiplegia & No & Yes & III ventricle & CH (old), gliosis \\
\hline 6 & 8 yr & $\mathbf{M}$ & Headache & Yes & No & $\mathbf{R}$ occipital & SAH (old), VH, R CH \\
\hline 7 & $9 \mathrm{yr}$ & $\mathbf{F}$ & $\begin{array}{l}\text { Headache } \\
\text { Coma }\end{array}$ & Yes & No & $\mathbf{R}$ basal ganglia & SAH, VH, infarction (old) \\
\hline 8 & $11 \mathrm{yr}$ & $\mathbf{M}$ & $\begin{array}{l}\text { Headache } \\
\text { Coma }\end{array}$ & Yes & No & L choroid plexus & $\begin{array}{l}\text { SAH, choroid plexus haemorrhage (old) } \\
\text { infarction, atrophy of cerebellum }\end{array}$ \\
\hline 9 & $12 \mathrm{yr}$ & $\mathbf{M}$ & $\begin{array}{l}\text { Seizure } \\
\text { Semicoma } \\
\text { R Hemiplegia }\end{array}$ & No & Yes & L temporoparietal & $\mathrm{CH}$, infarction \\
\hline 10 & $14 \mathrm{yr}$ & $\mathbf{M}$ & Headache & Yes & Yes & L frontoparietal & Basal ganglion $\mathrm{CH}$ (old, recent) \\
\hline 11 & $14 \mathrm{yr}$ & $\mathbf{F}$ & $\begin{array}{l}\text { L Facial Palsy } \\
\text { L Gaze Palsy } \\
\text { L Ophthalmoplegia }\end{array}$ & Yes & No & Brainstem & SAH, pontine $\mathrm{CH}$ (old, recent), $\mathrm{VH}$ \\
\hline 12 & $15 \mathrm{yr}$ & $\mathbf{M}$ & L Seizure & $\begin{array}{l}\text { Yes } \\
\text { (9yr and 15yr) }\end{array}$ & No & $\begin{array}{l}\text { Both hemispheres } \\
\text { and brainstem }\end{array}$ & SAH, CH (old, recent), diffuse infarction \\
\hline
\end{tabular}

SAH: Subarachnoid haemorrhage, VH: Ventricular haemorrhage,

Occasionally, astrogliosis was found between vessels (contiguous astrogliosis). In subject no 2 , a thin vessel-wall surrounding a thrombus which protruded into the ventricle was associated with perivascular haemorrhage.

The AVMs in six of the eight cases in group Il were confined to the cerebral hemispheres and brainstem (fig 1). The initial features in most children in group II had been headache, seizure, disturbance of consciousness, and hemiplegia: in subject no 3, the initial sign was hemiplegia only, at age two years and in subject no 12 , focal seizures at three years. The latter patient had

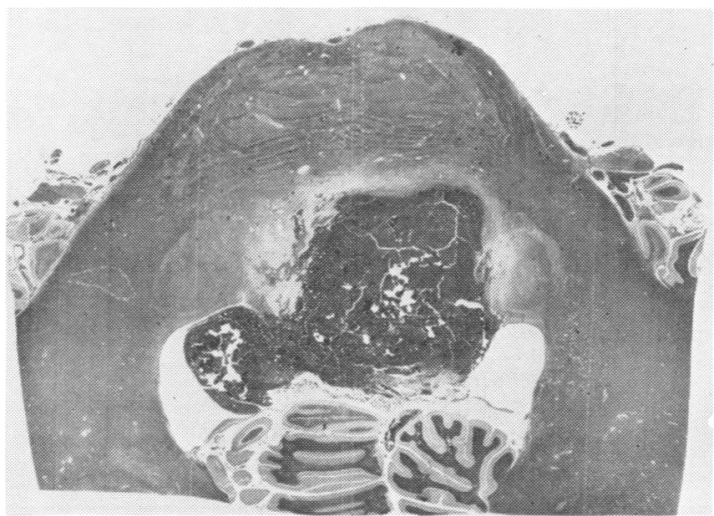

Fig 1 Haemorrhage with $A V M$ in the tegmentum of pons, with rupture into the fourth ventricle.

Luxol fast blue stain. $4 \times$.

\section{CH: Cerebral haemorrhage L: Left, R: Right}

undergone angiography at nine years and at 15 years; the second angiogram showed relative increase in the AVM's size.

At autopsy, seven subjects (not no 5) had had recent subarachnoid, ventricular, or cerebral haemorrhage, and seven (not no 9) had evidence of old haemorrhage (haemosiderin deposits) or old infarctions (gliosis in or around the vascular lesion). The AVMs had many thick-walled abnormal vessels without internal elastic lamina (fig 2). Aneurysmal dilation of arteries or veins

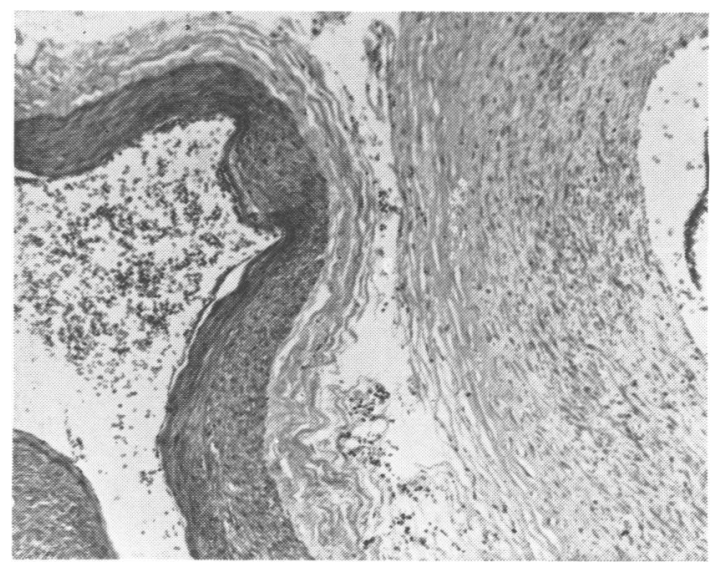

Fig 2 Lamination of elastic membrane in an artery (left) and fibrous mural thickening and absence of elastic lamina in an abnormal vessel (right). EVG stain. $100 \times$. 
was identified in four subjects. More marked in group II than in group I were tortuosity of vessels, vessel-wall thickness, thrombosis, contiguous gliosis, haemosiderin deposits, and vesselwall calcification.

2 Aneurysm of vein of Galen No children over age three years had died of AVG: death occurred most commonly in early infancy. Three subjects had had low Apgar scores, congestive heart failure soon after birth, and prenatal cerebral infarctions and died under the age of one week (group A; table 2). Cerebral angiograms and postmortem dissection of vessels showed feeding arteries, mainly from right and left anterior and posterior cerebral arteries. Old infarctions in subject no 2 were in the cerebral cortex and border zones between the middle and posterior cerebral arterial territories. Old cortical laminar

Table 2 Main features and test results in subjects wth aneurysms of the vein of Galen

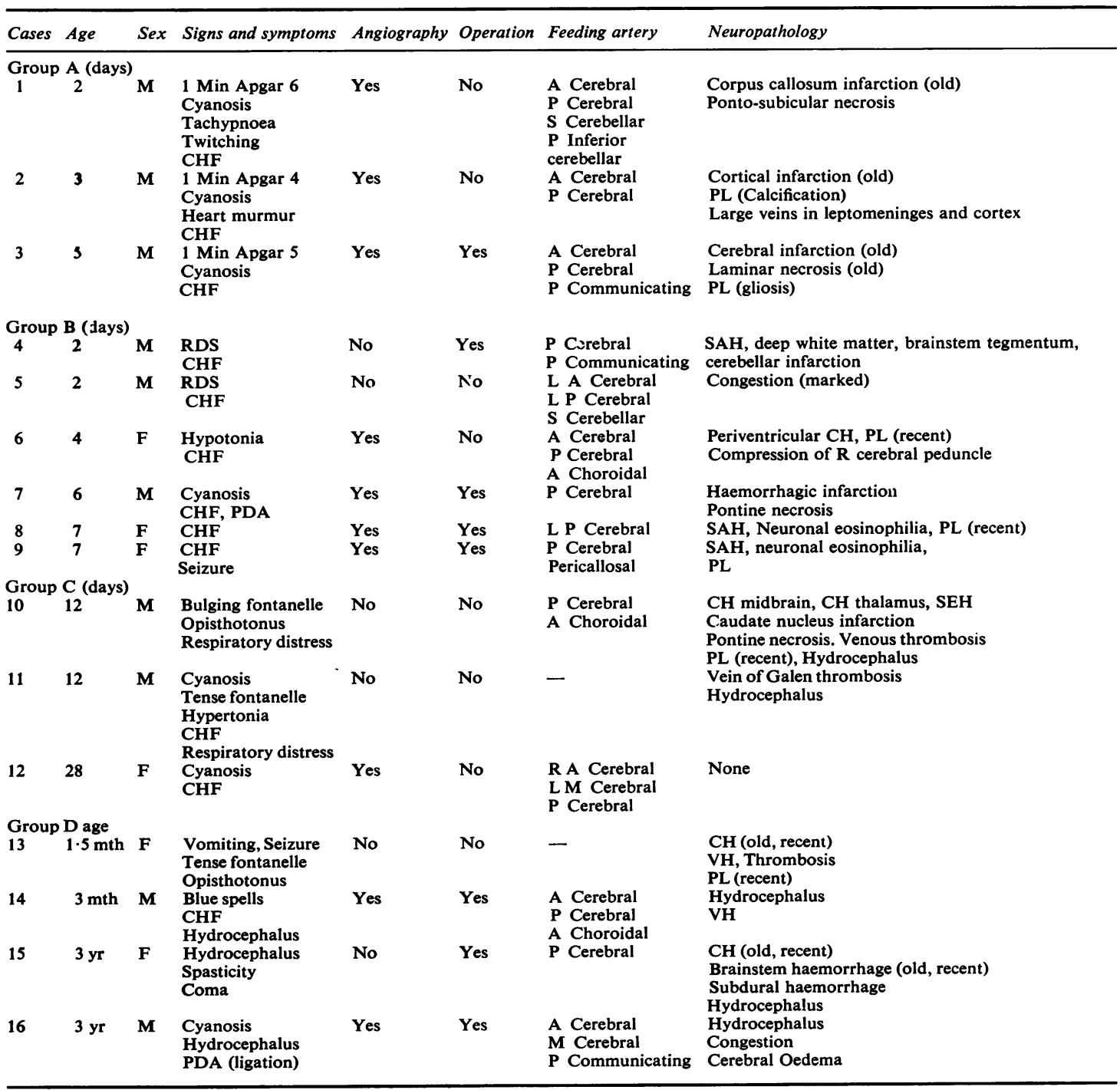

CHF: Congestive heart failure

PDA: Patent ductus arteriosus

RDS: Respiratory distress syndrome
A: Anterior
PL: Periventricular leukomalacia
M: Middle
P: Posterior
SEH: Subependymal haemorrhage
S: Superior 
necrosis was found at the border zone between the major cerebral arteries (fig 3). Old periventricular leukomalacia was also present.

Six subjects (cases 4 to 9) had had relatively high Apgar scores and experienced congestive heart failure several days after birth (group B). All died by the age of one week. Examination of their brains showed marked congestion, subarachnoid haemorrhage, periventricular leukomalacia, and hypoxic-ischaemic neuronal damage. Feeding arteries were one or both posterior cerebral arteries and, occasionally, anterior cerebral or other arteries.

Three children died at age one week to one month (group C). Two of these had had respiratory distress, cyanosis, tense fontanelle, and hypertonicity or opisthotonus. Also, they had thrombosis of vein of Galen or internal cerebral veins, karyorrhexis in pontine nuclei (fig 4) and periventricular leukomalacia. The third case had congestive heart failure but no neurological

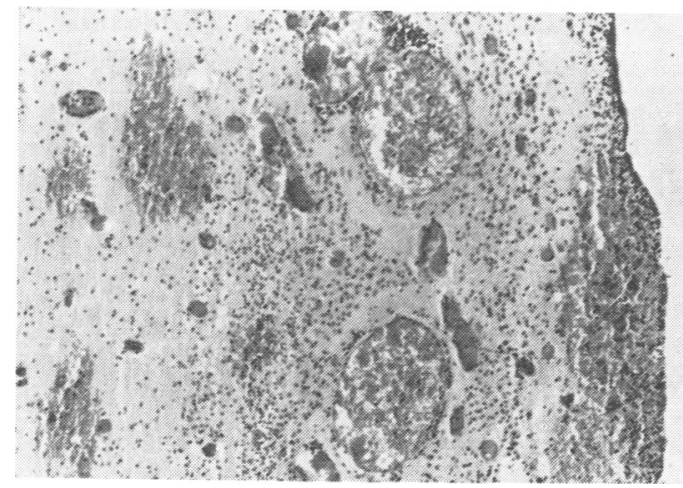

Fig 3 Old cortical laminar necrosis with neuronal loss, gliosis, and foam cells. H\&E stain. $60 \times$.

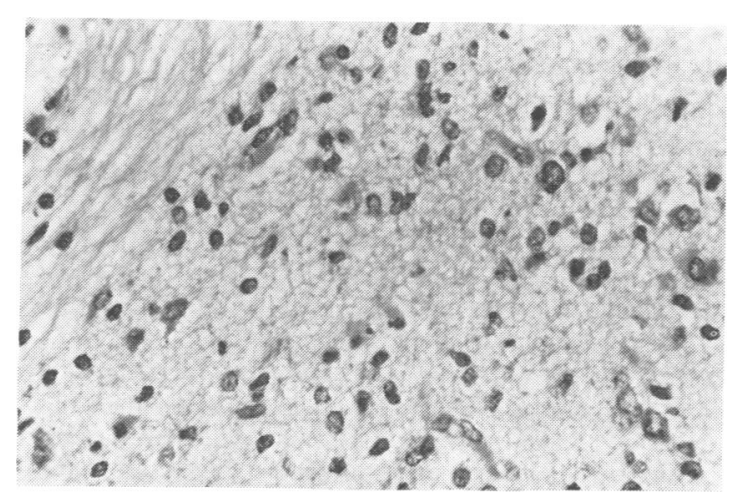

Fig 4 Group B, Case 10. Karyorrhexis in the pontine nuclei. H\&E stain. $200 \times$. abnormalities on examination.

The remaining four children were aged over one month at death (group D). Case 13 had been well until three days before death when she had seizures, opisthotonus, and a tense fontanelle. Lumbar and ventricular taps were bloody and the brain was markedly oedematous; an AVG with thrombosis was obvious. Thrombosed vessels were also found in the basal ganglia. In addition to ventricular haemorrhage, recent and old haemorrhagic infarction of basal ganglia, periventricular white matter and recent periventricular leukomalacia were present. The remaining three children in group D had hydrocephalus due to compression of the aqueduct of Sylvius by the AVG.

\section{Discussion}

During the early stage of foetal development, circulation occurs in a sponge-like mesh of thinwalled vascular channels which later become arteries, capillaries, and veins. If the normal mature vascular pattern and structure did not develop, primitive thin-walled tortuous vessels may remain as one or more AV shunts. ${ }^{2-6}$ The AV shunt demonstrated by cerebral angiography and histology is a primary change in the AVM, and the dilation and tortuosity of the surrounding vessels may be secondary. The size of the AVM gradually increases relatively or (rarely) decreases with age. ${ }^{6-9}$

1 Arteriovenous malformation Subjects in groups I and II did not differ in sex or location of AVM. In each group, one quarter of the cases involved the brainstem. In group II, there was a greater incidence of documented localised neurological deficit; all cases had had haemorrhage into either the subarachnoid space or the brain, and cerebral infarction (recent or old) was more common.

Dilated and tortuous veins with abnormal arteries were present in the histological sections. In both age groups there were tortuous veins with intimal thickening, mural fibrosis, narrowing of lumen, and arterialisation (with increased amounts of elastic tissue) of veins. The latter change presumably was caused by increased blood volume and pressure. In the arteries there was thickening or thinning of the wall and lamination or focal absence of elastic lamina. Changes in veins were more marked than in arteries.

In AVMs, there was evidence of prior vascular compression, ischaemia, or haemorrhage in the intervening neural tissue. ${ }^{19}$ Loss of neurons, gliosis, foam cells and demyelination were easily 
recognised. Fibrous thickening, calcification of vascular wall, thrombosis, gliosis, and haemosiderin deposits in intervening neural tissue were more marked in group II than in group I. These old changes of vascular wall and intervening neural tissue may be related to enlargement or regression in size of the AVM.

2 Aneurysm of vein of Galen There is a male predominance both in subjects who died under one week of age (groups A and B) and in older subjects (groups $\mathrm{C}$ and $\mathrm{D}$ ). There were more newborns (aged less than one month) affected than older children. This contrasts with the subjects with AVM: almost all our subjects with AVM were older than any of our subjects with AVG. Congenital heart failure is more common in the newborns than the older children. In contrast, hydrocephalus is more common in the older age group, although there is considerable overlap.

Pathological correlation of structural damage in AVG has been documented by Norman and Becker. ${ }^{10}$ Their autopsy findings in seven neonatal cases included haemorrhage, infarction, periventricular leukomalacia and cortical laminar necrosis. They believed the mechanisms of damage were: (1) a "steal" phenomenon in overlying abnormal vessels, (2) ischaemia or failure of perfusion, due to congestive heart failure, (3) thrombosis of venous aneurysm, (4) atrophy of adjacent structures due to compression, (5) alteraof flow, caused by operative intervention. ${ }^{10} 11$

Congestive heart failure occurs in the neonate or infant as a consequence of rapid AV shunting through a cerebral AVM. ${ }^{10}{ }^{12-18}{ }^{22}$ Because blood flows from high pressure areas to low pressure areas and subjects in group A had prominent AV shunts, ischaemia or hypoperfusion occurred at border zones between major cerebral arteries. In group A infarction occurred, but, in groups $B, C$, and $D$, haemorrhage was more frequent either with or without infarction.

Thrombosis of deep cerebral veins, the vein of Galen, or sinus system has been reported in some subjects with AVG ${ }^{19} \mathbf{2 0}$; occasionally, thrombosis is associated with venous infarction. ${ }^{21}$ Three cases in groups $\mathbf{C}$ and $\mathbf{D}$ had thrombosis of deep cerebral veins and vein of Galen. The vessel wall of the cases in group $C$ showed slight intimal thickening of the vein of Galen, especially immediately distal to the AV shunt; this thickening increased with ageing. These vascular changes may be contributed to by the formation of thrombus. As the aneurysmal sac increased in size, it compressed neighbouring structures of the brain; the quadrigeminal plate was particularly affected and the aqueduct of Sylvius was compressed and displaced, producing internal hydrocephalus. Manifestation of this disease process in older infants and children is commonly by way of hydrocephalus rather than predominantly by heart failure.

In summary, in terms of the main two types of pathology, haemorrhage and infarction, $100 \%$ of cases with AVM had haemorrhage and $50 \%$ of cases with AVG had haemorrhage; $40 \%$ of cases with AVM had infarction and $70 \%$ of cases with AVG had infarction.

\section{References}

1 McCormick WF. The pathology of vascular ("arteriovenous") malformations. J Neurosurg 1966; 24:807-16.

2 Padget DH. The cranial venous system in man in reference to development, adult configuration, and relation to the arteries. Am J Anat 1956; 98:307-55.

3 Padget DH. The development of the cranial venous system in man, from the viewpoint of comparative anatomy. Contr Embryol Carnegie Inst 1957; 36:79-140.

4 Kaplan HA, Aronson SM, Browder EJ. Vascular malformations of the brain. An anatomical study. $J$ Neurosurg 1961; 18:630-5.

5 O'Brien MS, Schechter MM. Arteriovenous malformations involving the Galenic system. Am J Roentgenol 1970; 110:50-5.

6 Vinken PJ, Bruyn GW, eds. Vascular Diseases of the Nervous System. Handbook of Clinical Neurology, vols 11-12. Amsterdam: North Holland, 1972.

7 Conforti P. Spontaneous disappearance of cerebral arteriovenous angioma; case report. J Neurosurg 1971; 34:432-4.

8 Hansen JH, Søgaard I. Spontaneous regression of an extra- and intracranial arteriovenous malformation. Case report. J Neurosurg 1976; 45: 338-41.

9 Svien HJ, Peserico L. Regression in size of arteriovenous anomaly. J Neurosurg 1960; 17: 493-6.

10 Norman MG, Becker LE. Cerebral damage in neonates resulting from arteriovenous malformation of the vein of Galen. J Neurol Neurosurg Psychiatry 1974; 37:252-8.

11 Kelly JJ, Mellinger JF, Sundt TM, Jr. Intracranial arteriovenous malformations in childhood. Ann Neurol 1978; 3:338-43.

12 Gomez MR, Whitten CF, Nolke A, Berstein J, Meyer JS. Aneurysmal malformation of the great vein of Galen causing heart failure in early infancy. Report of five cases. Pediatrics 1963; 31:400-11.

13 Carrol CPH, Jakoby RK. Neonatal congestive heart failure as the presenting symptom of cere- 
bral arteriovenous malformation. J Neurosurg 1966; 25:159-63.

14 Claireaux AE, Newman CGH. Arteriovenous aneurysm of the great vein of Galen with heart failure in the neonatal period. Arch Dis Child $1960 ; 35: 605-12$.

15 Corrin B. Three cases of intracranial vascular malformations in infants. J Clin Pathol 1959; 12:412-8.

16 Glatt BS, Rowe RD. Cerebral arteriovenous fistula associated with congestive heart failure in the newborn: report of two cases. Pediatrics 1960; 26:596-603.

17 Holden AM, Fyler DC, Shillito J, Jr, Nadas AS. Congestive heart failure from intracranial arteriovenous fistula in infancy: clinical and physiologic considerations in eight patients. Pediatrics 1972; 49:30-9.
18 Pollock AQ, Laslett PA. Cerebral arteriovenous fistula producing cardiac failure in newborn infants: case report and review. J Pediatr 1958; 53:731-6.

19 Silverman BK, Breck T, Craig J, Nadas AS. Congestive failure in the newborn caused by cerebral A-V fistula. Am J Dis Child 1955; 89: $539-43$

20 Gold AP, Ransohoff J, Carter S. Vein of Galen malformation. Acta Neurol Scand 1964; suppl 11, 40:1-31.

21 Stern L, Ramos AD, Wiglesworth FW. Congestive heart failure secondary to cerebral arteriovenous aneurysm in the newborn infant. $\mathrm{Am} \mathrm{J}$ Dis Child 1968; 115:581-7.

22 Hirano A, Solomon S. Arteriovenous aneurysm of the vein of Galen. Arch Neurol 1960; 3:58993. 